\title{
Cyclical etidronate use is not associated with symptoms of peptic ulcer disease
}

Received: 11 October 1999 / Accepted: 15 March 2000

\begin{abstract}
Objective: To investigate whether the alkylbisphosphonate etidronate is associated with an increased risk of gastrointestinal symptoms.

Methods: We conducted an observational follow-up study on a possible relationship between etidronate use and the risk of gastrointestinal symptoms in a cohort of 2754 women over 50 years of age. The study was performed with data on drug prescriptions obtained from the PHARMO database in the Netherlands. Women were included when they used either cyclical etidronate $(n=1050)$ or estrogen $(n=1704)$ for at least 14 days. They were followed-up for incident use of antiulcer drugs while on exposure medication.

Results: The mean ages were 72 years and 59 years in the etidronate and estrogen groups, respectively. In total, there were 95 women with incident prescriptions for gastrointestinal events after a median duration of follow-up of 2.7 months (range 0.1-19.4 months). The crude relative risk of a gastrointestinal event for etidronate compared with estrogen use was 1.2 [95\% confidence interval (95\% CI) 0.8-1.8]. Adjusted for baseline age, use of corticosteroids, salicylates and nonsteroidal anti-inflammatory drugs, the relative risk reversed to 0.6 (95\% CI 0.4-1.2).

Conclusion: The use of cyclical etidronate is not associated with an elevated risk of symptoms of peptic ulcer disease.
\end{abstract}

H. Burger · R. M. C. Herings · A. C. G. Egberts

H. G. M. Leufkens

Department of Pharmacoepidemiology and Pharmacotherapy,

Utrecht University, Utrecht, The Netherlands

C. Neef

Medicines Evaluation Board, The Hague, The Netherlands

H. Burger $(\bowtie)$

Julius Center for Patient Oriented Research,

University Medical Center Utrecht, PO Box 85500 ,

3508 GA, Utrecht, The Netherlands

e-mail: H.Burger@jc.azu.nl

Tel.: +31-30-2509358; Fax: +31-30-2505480
Key words Osteoporosis · Treatment .

Bisphosphonates

\section{Introduction}

Osteoporosis is a major public health problem, particularly in the Westernized societies. It was recently estimated that, in the United States, each year around 1.5 million bone fractures are attributable to osteoporosis [1]. The health care costs associated with these osteoporotic fractures amount to approximately US \$14 billion [2]. Therefore, several strategies to prevent fractures have been advocated, including pharmacotherapeutic interventions aiming at inhibition of bone resorption. Among these, the bisphosphonates etidronate and alendronate take a prominent place. They have shown convincing therapeutic efficacy and they are increasingly prescribed for the treatment of established osteoporosis [3-5]. However, the use of the aminobisphosphonate alendronate has been repeatedly associated with severe gastrointestinal side effects such as erosive esophagitis [6-9]. These observations have raised the question whether the use of its predecessor, the alkylbisphosphonate etidronate, is associated with gastrointestinal damage as well. Although randomized clinical trials with etidronate do not support such a hypothesis $[4,5,10,11]$, they were generally too small and too much confined to relatively healthy people to arrive at a sufficiently grounded conclusion on this presumed side effect. As far as we know, there has been only one population-based study on this issue [12]. This study showed no excess risk of major gastrointestinal events in etidronate users but gives no information on minor events and needs confirmation.

We conducted an observational follow-up study on the relationship between etidronate use and the risk of gastrointestinal symptoms in a cohort of 2754 women over 50 years of age. 


\section{Methods}

\section{Population}

The present study was performed with data from the PHARMO record-linkage system. This system provides information on hospital admissions and drug prescriptions in a dynamic population of approximately 450,000 residents of 12 middle-sized Dutch cities from 1985 onward $[13,14]$. Women over 50 years of age who were part of the PHARMO population for at least 1 month were eligible and were subsequently included if they had had an episode of etidronate or estrogen use. An episode of drug use was defined as use for at least 14 days and lasted from the initial prescription to the date of stopping the drug. The stopping date was defined as the start of the first period of not taking the drug for 30 days or more. The exposed group consisted of those who had at least one episode of cyclical etidronate use (14 days of etidronate followed by 76 days of calcium). To allow valid comparison, the reference group was chosen to consist of women probably treated for osteoporosis [15]. Therefore, we selected as a reference group women who had at least one episode of either estradiol or conjugated estrogen use, i.e., estrogens labeled for, among other indications, osteoporosis. We assumed that these estrogens themselves are not related to the development of gastrointestinal symptoms.

The beginning date of the first episode of either index or reference medication use was taken as the date of entry into the cohort, i.e., baseline. Entry into the study was stopped on 12 June 1996. Cohort members were followed up for first gastrointestinal events, i.e., episodes of antiulcer medication defined as those drugs that were commonly prescribed for peptic ulcer disease during follow-up. These drugs were antacids, histamine $\mathrm{H}_{2}$-receptor antagonists, gastric acid pump inhibitors, and gastric mucosa protectants. Follow-up ended either with the gastrointestinal event or, when later, with censoring at the end of the etidronate or estrogen episode. To allow statistically reliable risk comparison between the two groups, observations were also censored after 20 months of follow-up, as by that time there appeared to be less than 100 subjects at risk in each group. This moment was arbitrarily chosen. A total of 3684 women with exposure or reference medication were included in the cohort. We excluded 812 women with a history of antiulcer drug use and 118 women who had an episode of both etidronate and estrogen use during the study. The remainder of 1050 etidronate and 1704 estrogen users were analyzed.

\section{Data analysis}

The focus was on time-to-event or 'survival' analysis. Life tables were constructed to calculate the cumulative risk of a gastrointestinal event as a function of time since baseline. Hazard ratios from proportional hazards models were calculated as measures of relative risk and were presented with a $95 \%$ confidence interval $(95 \%$ CI). In order to adjust for potential confounding, we additionally included indicator variables for baseline 5-year age groups and use of corticosteroids, salicylates, or nonsteroidal anti-inflammatory drugs. The estimated cumulative probability of starting antiulcer drugs in each group was plotted against time of observation. Logminus-log plots showed appropriateness of proportional hazards models.

\section{Results}

Table 1 shows baseline characteristics for etidronate and estrogen users. Etidronate users were at baseline substantially older than users of estrogen, with mean (range) ages 72 years (54-95 years) and 59 years $(50$ 91 years), respectively. In the etidronate group, a considerably larger proportion than in the estrogen group
Table 1 Baseline characteristics. NSAIDS nonsteroidal anti-inflammatory drugs

\begin{tabular}{lcl}
\hline Age (years) & $\begin{array}{l}\text { Etidronate }(n=1050) \\
\text { no. }(\%)\end{array}$ & $\begin{array}{l}\text { Estrogen }(n=1704) \\
\text { no. }(\%)\end{array}$ \\
\hline $50-54$ & $4(4)$ & $430(25)$ \\
$55-59$ & $68(7)$ & $743(44)$ \\
$60-64$ & $157(15)$ & $314(18)$ \\
$65-69$ & $201(19)$ & $132(8)$ \\
$70-74$ & $245(23)$ & $44(3)$ \\
$\geq 75$ & $375(36)$ & $41(2)$ \\
Co-medication & & \\
$\quad$ Corticosteroids & $23(2)$ & $10(1)$ \\
$\quad$ Salicylates & $27(3)$ & $12(1)$ \\
$\quad$ NSAIDS & $98(9)$ & $40(2)$ \\
\hline
\end{tabular}

was using corticosteroids, salicylates, or nonsteroidal anti-inflammatory drugs.

The median (range) duration of follow-up in the etidronate and estrogen group was 5 months $(0.1-$ 20 months) and 3 months ( $0.2-20$ months), respectively. In total there were 95 women with incident gastrointestinal events. The events occurred on the median (range) 2.7 months (0.1-19.4 months) after baseline [3.7 months (0.1-17.3 months) in the etidronate and 2.3 months (0.2-19.4 months) in the estrogen users]. After 12 months, the cumulative risk of a gastrointestinal event was $8 \%$ in the etidronate group, and $6 \%$ in the estrogen group. After 18 months, these risks were $11 \%$ and $10 \%$, respectively.

The unadjusted relative risk of a gastrointestinal event for etidronate compared with estrogen use was 1.2 (95\% CI 0.8-1.8). When adjusted for age only, this relative risk reversed to 0.7 (95\% CI $0.4-1.2)$ and additional adjustment for baseline use of corticosteroids, salicylates, or nonsteroidal anti-inflammatory drugs changed it to 0.6 (95\% CI 0.4-1.2). Adjustment for prescriber did not affect the results. None of the above relative risks was statistically significant. Figure 1 illustrates for each group the estimated cumulative probability of an incident gastrointestinal event by follow-up time, after adjustment for baseline age, use of corticosteroids, salicylates, and nonsteroidal anti-inflammatory drugs. It shows that, throughout the follow-up period, the risks were slightly higher for the estrogen users than for those taking etidronate.

\section{Discussion and conclusions}

In the present study, we show that etidronate use is not related to an increased risk of peptic ulcer disease compared with estrogen in a large cohort of women aged 50 years or over. An important advantage of this study is that it was conducted among members of the general drug-taking population, thus disposing of the problems of inference from randomized clinical trials that are commonly conducted in relatively healthy persons only. Further, the cohort design allowed us to 


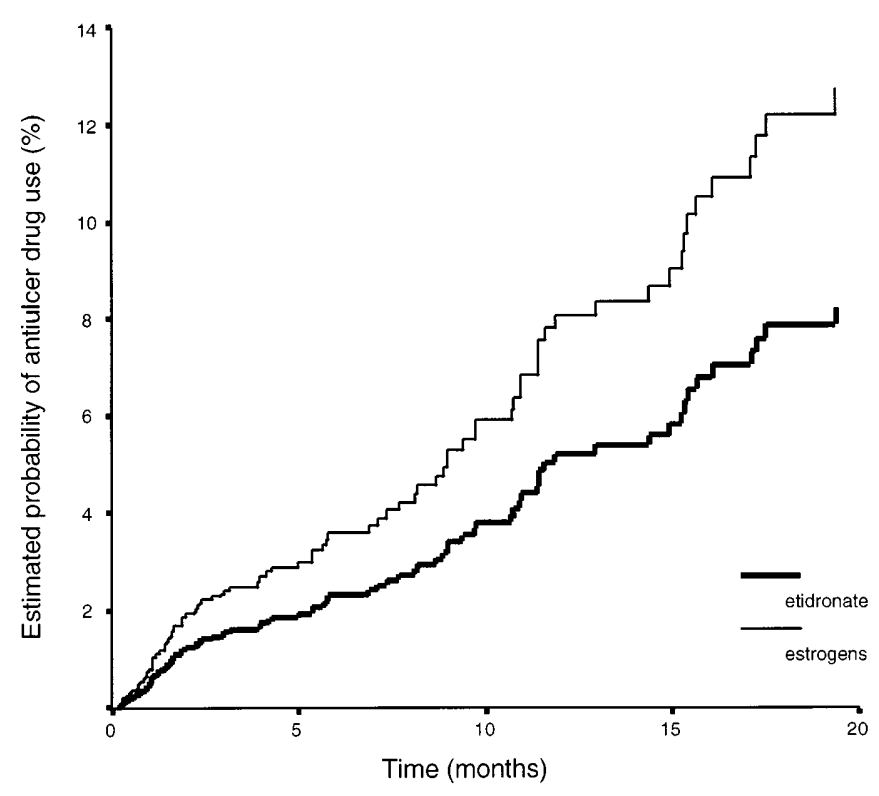

Fig. 1 The estimated cumulative probability of an incident gastrointestinal event by follow-up time, after adjustment for age and use of corticosteroids, salicylates, and nonsteroidal anti-inflammatory drugs

estimate absolute risks of gastrointestinal events during treatment.

Some limitations of this study should be discussed before our findings can be accepted. For valid comparison, it is essential that both groups have, apart from the exposure medication, an identical risk of the outcome. In our study, severity of osteoporosis may have jeopardized this prerequisite, thus confounding the underlying true relationship. First, the type of drug prescribed for osteoporosis was most likely related to severity of this disease, namely estrogen for early stage osteoporosis or merely menopausal symptoms [16] and bisphosphonates for established osteoporosis [15]. Second, severity of osteoporosis may relate to backpain [17] and thereby to painkilling drugs that are known to be associated with gastrointestinal events [18]. Third, the severity of osteoporosis itself may be positively associated with the risk of gastrointestinal events [19]. Although we adjusted for confounders that are probably correlates of severity of osteoporosis, in particular age and the use of salicylates and nonsteroidal anti-inflammatory drugs, we had no data on severity itself, so the adjustment may have been incomplete. However, adjustment for such residual confounding would have resulted in an even lower relative risk of gastrointestinal symptoms in the etidronate group.

A further limitation is that we were not able to detect peptic ulcer disease or dyspeptic symptoms in a patient directly, but instead we used a marker for them, i.e., the patient having a prescription for a drug that was commonly given for these conditions at the time of the study. While it is beyond doubt that antacid therapy should be part of every antiulcer treatment strategy [18], it is unlikely that all patients treated with these drugs actually had peptic ulcer disease. This is supported by the fact that the incidence of peptic ulcer disease in women from the Netherlands is much lower than the incidence of antiulcer agents in this study, namely around 0.9 per 1000 person-years [20]. Misclassification of gastrointestinal events by using drugs as markers may have been non-random if doctors were aware of the potentially unfavorable effects of bisphosphonates on the gastrointestinal tract. If so, they may have been more inclined to prescribe antiulcer drugs in etidronate than in estrogen users and, again, the true relative risk of gastrointestinal events in the etidronate users would be even lower. Further, etidronate may have been preferentially prescribed to those with a relatively small risk of gastrointestinal problems compared with estrogen users. However, we limited the potential for such bias by restricting our study to those patients without a history of antiulcer drug use. Further, the data do not support this bias, as a larger proportion of the etidronate group than the estrogen group used drugs that increased the risk of gastrointestinal events. We included only those gastrointestinal events that occurred while using etidronate or estrogen.

Although it cannot be excluded that long-term effects occur after stopping the drug, this restriction allows attribution of events to the medication under study with greater confidence and, moreover, gastric mucosal injury during alendronate use has been shown to occur almost instantaneously after starting the drug [9]. Finally, it remains possible that etidronate was stopped because of imminent gastrointestinal symptoms before antiulcer drugs were prescribed. Unfortunately, information on the reasons for discontinuation of medication was not available.

The results of our study are in agreement with numerous clinical trials on the efficacy of etidronate $[4,5$, $10,11]$. Further, the results are in accordance with at least one other population-based study showing approximately equal incidence rates of upper gastrointestinal events in users of etidronate and those with a diagnosis of osteoporosis without taking etidronate [12]. As far as we know, there are no other population-based studies that corroborate or refute our findings. Although it is inexpedient to exclude an increased risk of a certain adverse event, for etidronate it seems reasonable now to consider this drug as safe, at least with regard to the gastrointestinal tract.

In conclusion, this study shows that the use of cyclical etidronate in combination with a calcium salt is not associated with an excess risk of gastrointestinal symptoms requiring the use of antiulcer drugs.

Acknowledgements This work was supported by a grant from the Dutch Medicines Evaluation Board. Further, we would like to thank Dr A.W. Broekmans for his critical review of the manuscript.

\section{References}

1. Riggs BL, Melton LJ III (1995) The worldwide problem of osteoporosis: insights afforded by epidemiology. Bone 17 [Suppl 5]: 505S-511S 
2. Ray NF, Chan JK, Thamer M, Melton LJ III (1997) Medical expenditures for the treatment of osteoporotic fractures in the United States in 1995: report from the National Osteoporosis Foundation. J Bone Miner Res 12: 24-35

3. Black DM, Cummings SR, Karpf DB, et al (1996) Randomised trial of effect of alendronate on risk of fracture in women with existing vertebral fractures. Fracture Intervention Trial Research Group. Lancet 348: 1535-1541

4. Miller PD, Watts NB, Licata AA, et al (1997) Cyclical etidronate in the treatment of postmenopausal osteoporosis: efficacy and safety after seven years of treatment. Am J Med 103: 468-476

5. Montessori ML, Scheele WH, Netelenbos JC, Kerkhoff JF, Bakker K (1997) The use of etidronate and calcium versus calcium alone in the treatment of postmenopausal osteopenia: results of three years of treatment. Osteoporos Int 7: 52-58

6. Jeal W, Barradell LB, McTavish D (1997) Alendronate. A review of its pharmacological properties and therapeutic efficacy in postmenopausal osteoporosis Drugs 53: 415-434

7. Adami S, Zamberlan N (1996) Adverse effects of bisphosphonates. A comparative review. Drug Saf 14: 158-170

8. de Groen PC, Lubbe DF, Hirsch LJ, et al (1996) Esophagitis associated with the use of alendronate. $\mathrm{N}$ Engl $\mathbf{J}$ Med 335: 1016-1021

9. Graham DY, Malaty HM, Goodgame R (1997) Primary amino-bisphosphonates: a new class of gastrotoxic drugs - comparison of alendronate and aspirin. Am J Gastroenterol 92: $1322-1325$

10. Roux C, Oriente P, Laan R, et al (1998) Randomized trial of effect of cyclical etidronate in the prevention of corticosteroidinduced bone loss. Ciblos Study Group. J Clin Endocrinol Metab 83: 1128-1133
11. Lyritis GP, Tsakalakos N, Paspati I, et al (1997) The effect of a modified etidronate cyclical regimen on postmenopausal osteoporosis: a four-year study. Clin Rheumatol 16: 354-360

12. van Staa T, Abenhaim L, Cooper C (1997) Upper gastrointestinal adverse events and cyclical etidronate. Am J Med 103: $462-467$

13. Herings RMC, De Boer A, Stricker BHC, et al (1995) Hypoglycaemia associated with use of inhibitors of angiotensin converting enzyme. Lancet 345: 1195-1198

14. Herings RMC, Leufkens HGM (1998) Community pharmacy networks in pharmacoepidemiology. In: Hartzema AG, Porta M, Tilson HH (eds) Pharmacoepidemiology. An introduction. Harvey Whitney Books Company, Cincinnati, pp 405-420

15. Lindsay R (1993) Prevention and treatment of osteoporosis. Lancet 341: 801-805

16. Jacobs S, Hillard TC (1996) Hormone replacement therapy in the aged. Drugs Aging 8: 193-213

17. Burger H, van Daele PLA, Grashuis K, et al (1997) Vertebral deformities and functional impairment in men and women. J Bone Miner Res 12: 152-157

18. Soll AH (1996) Consensus conference. Medical treatment of peptic ulcer disease. Practice guidelines. Practice parameters committee of the American College of Gastroenterology. JAMA 275: 622-629

19. Hawker GA (1996) The epidemiology of osteoporosis. J Rheumatol 45 [Suppl]: 2-5

20. Festen HPM (1997) Gastric and duodenal ulcers. In: Maas IAM, Gijsen R, Lobbezoo IE, Poos MJJC (eds) Public health status and forecasts 1997 (in Dutch). Rijksinstituut voor Volksgezondheid en Milieuhygiëne (National Institute of Public Health and the Environment)/Elsevier, Maarssen, pp 517-523 